\title{
EFICIÊNCIA DA CLORAÇÃO DA ÁGUA DE IRRIGAÇÃO NO TRATAMENTO DE GOTEJADORES COM ENTUPIMENTO DE CAUSA BIOLÓGICA ${ }^{1}$
}

\author{
Ronaldo Souza Resende ${ }^{2}$, Rubens Duarte Coelho $^{3}$ \& Sônia Maria de Stéfano Piedade ${ }^{4}$
}

\begin{abstract}
RESUMO
Com o propósito de se avaliar a eficiência de diferentes dosagens de cloro na desobstrução por tratamento de choque de gotejadores, conduziu-se um experimento no Laboratório de Irrigação do Departamento de Engenharia Rural da Escola Superior de Agricultura “Luiz de Queiroz"- ESALQ/USP, no qual foram utilizados os seguintes tipos de gotejador Netafim: Streamline 100, Ram 17L, Dripline 2000, Tiran 17 e Typhoon 20, e avaliadas as dosagens de cloro de 150,300, 450 e $600 \mathrm{mg} \mathrm{L}^{-1}$. A água utilizada no ensaio foi proveniente de fonte hídrica superficial, aproveitada para irrigação. Para os tratamentos de recuperação dos emissores, utilizou-se o hipoclorito de sódio comercial (12\%) como fonte de cloro, aplicado continuamente por $60 \mathrm{~min}$, e logo após, deixou-se o produto interagir por $12 \mathrm{~h}$ na mangueira, sem fluxo na rede. Para todos os emissores, exceto o Streamline, a aplicação de cloro resultou em aumento da vazão média. Para o modelo Dripline, o tratamento com cloro reduziu a uniformidade de emissão e a eficiência da cloração aumentou após a segunda aplicação, para o modelo Tiran.
\end{abstract}

Palavras-chave: hipoclorito de sódio, desobstrução, irrigação localizada

\section{EFFICIENCY OF CHLORINATION OF IRRIGATION WATER AS A TREATMENT FOR CLOGGED EMITTERS FROM BIOLOGICAL CAUSES}

\begin{abstract}
An experiment was conducted at the Laboratory of Irrigation in the Department of Rural Engineering at ESALQ, in order to evaluate the use of different chlorine doses in recovering the original flow rate for total and partial emitter clogging. Five Netafim drippers were evaluated: Streamline 100, Ram 17L, Dripline 2000, Tiran 17 and Typhoon 20. Four chlorine levels, 150, 300, 450 and $600 \mathrm{mg} \mathrm{L}^{-1}$, were tested. A regular water source for irrigation was used. Sodium hypoclorite $(12 \%)$ was used as the source of chlorine supply. The chlorination process took place during $60 \mathrm{~min}$ and after this period the solution remained inside the hose for $12 \mathrm{~h}$ without flow. Then the flow of each emitter was measured. Mean discharge, variation coefficient of mean discharge, percentage of number of emitters in different classes of discharge reduction were analyzed. For all kinds of drippers, except the Streamline, the chlorine treatment improved the discharge rate. For the Dripline model the treatment reduced the uniformity emission, while eficiency was increased after the second application for the Tiran model.
\end{abstract}

Key words: sodium hypoclorite, reclaiming, drip

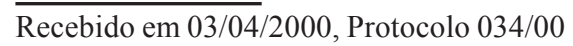

${ }^{1}$ Parte de Dissertação de Mestrado apresentada à Escola Superior de Agronomia “Luiz de Queiroz" - ESALQ, pelo primeiro autor

${ }^{2}$ Eng. Agr. M.Sc. Irrigação e Drenagem, COHIDRO-SE. Doutorando do DER/ESALQ/USP. Av. Pádua Dias, 11, CEP 13416 - 150, Piracicaba, SP. Fone: (0xx19) 429 4217, Fax: (0xx19) 422 5925. E-mail: rsrezend@ carpa.ciagri.usp.br

${ }^{3}$ Professor Doutor do Departamento de Engenharia Rural da ESALQ/USP. Fone: (0xx19) 429 4217. E-mail: rdcoelho@carpa.ciagri.usp.br

${ }^{4}$ Professora Doutora do Departamento de Ciências Exatas da ESALQ/USP. Fone: (0xx19) 429 4127. E-mail: soniamsp@carpa.ciagri.usp.br 


\section{INTRODUÇÃO}

O tratamento de água comumente efetuado em projetos de irrigação localizada inclui apenas a filtração da água utilizada através de filtros de areia tela ou discos. Diversos trabalhos têm apontado para o fato de apenas a filtragem da água ser insuficiente para prevenir o entupimento de emissores (Gilbert et al., 1979; Gilbert et al., 1982; Gilbert \& Ford, 1986). Águas com alta incidência populacional de algas e bactérias são passíveis de originar cimentação da areia dentro do filtro, resultante da formação de mucilagem, originando caminhos preferencias e reduzindo, assim, a eficiência de filtragem (Ravina et al., 1992). Como agravante, o alto custo de filtros de areia dotados de retrolavagem automática faz com que muitos irrigantes utilizem apenas filtros de tela ou discos. Desta forma, o entupimento de emissores tem-se constituído em ocorrência generalizada nos sistemas de irrigação localizada e o problema, embora existente, mantém-se, muitas vezes, pouco percebido, dado ao fato dos irrigantes não terem a avaliação sistemática da uniformidade de emissão de água dos projetos como prática de rotina

De modo geral, o elenco de medidas deve incluir o tratamento químico da água, sendo a acidificação e a cloração os tratamentos mais utilizados para controlar o entupimento de origem biológica. A principal recomendação tanto na prevenção como na recuperação de emissores com entupimento causado por algas e bactérias, são aplicações de cloro, comumente na forma de hipoclorito de sódio, hipoclorito de cálcio ou gás cloro. Assim, Pizarro (1996) recomenda, para a recuperação de emissores parcialmente entupidos, a aplicação, durante $12 \mathrm{~h}$, de concentrações de cloro de 250 a $500 \mathrm{mg} \mathrm{L}^{-1}$, seguida de lavagem das redes.

O uso de hipoclorito de sódio a $500 \mathrm{mg} \mathrm{L}^{-1}$, sulfato de cobre a $1 \%$ e ácido clorídrico a $2 \%$, foi avaliado por Padmakumari \& Sivanappan (1985) para a recuperação de gotejadores entupidos e observaram que o tratamento com hipoclorito de sódio foi o mais efetivo para aumentar a vazão dos emissores. Do mesmo modo, English (1985) recomenda tratamento com cloro a uma taxa de $500 \mathrm{mg} \mathrm{L}^{-1}$, para a recuperação de emissores severamente afetados por bactérias e algas.

Emissores apresentando redução de vazão de 25 a 50\% foram tratados por Nakayama et al.(1977) com a utilização de cloro, na concentração de $100 \mathrm{mg} \mathrm{L}^{-1}$. Este tratamento resultou em um retorno do funcionamento dos emissores a um nível de aproximadamente $95 \%$ da vazão inicial. Superclorações de até $1000 \mathrm{mg} \mathrm{L}^{-1}$ foram citadas por Gilbert \& Ford (1986) para a recuperação de emissores parcialmente entupidos. Tais autores ressaltam, porém, o risco de injúria às raízes das plantas. Adicionalmente, superdosagens podem afetar a membrana de borracha natural de emissores autocompensantes.

De modo geral, o tratamento com utilização combinada de ácido e cloro apresenta maior eficiência, em relação ao uso exclusivo de ácidos ou cloro. A dosagem a ser aplicada, tanto de cloro como de ácido, deve ser calculada conforme a qualidade da água, uma vez que águas de diferentes qualidades apresentam específicas demandas por cloro e por ácido, para atingirem valores predeterminados de cloro residual e $\mathrm{pH}$.
O objetivo deste trabalho foi avaliar a eficiência do processo de cloração, através de diferentes dosagens de hipoclorito de sódio, na recuperação de gotejadores apresentando entupimento, total ou parcial, de causa biológica.

\section{MATERIAL E MÉTODOS}

Em uma bancada de ensaio construída no Laboratório de Irrigação do Departamento de Engenharia Rural da ESALQ, cinco modelos de gotejadores foram submetidos a um tempo de operação de 2160 h, com uso de uma água na qual o nível populacional de bactérias era superior a $5,0 \times 10^{4} \mathrm{UFC} \mathrm{\textrm {mL } ^ { - 1 }}$ (Unidades Formadoras de Colônias por mililitro de água). A manutenção dessa população foi obtida através de inoculações de meio de cultura de bactérias isoladas em água superficial. $\mathrm{Na}$ bancada, construída em madeira com dimensões de $6 \mathrm{~m}$ de comprimento x 1,3 m de largura e 1,45 m de altura, foi montada uma estrutura hidráulica constituída de 4 blocos instalando-se, em cada bloco, 5 linhas de gotejadores de cada um dos modelos (Figura 1); cada linha foi composta por 50 gotejadores; para isto, as mangueiras com o espaçamento original entre emissores foram cortadas e remontadas, utilizando-se uniões de mangueira, resultando em um espaçamento único entre gotejadores, de 0,11 m para todos os modelos; a água, após passar através dos gotejadores, era recolhida por uma calha que a reconduzia ao tanque de captação constituindo, assim, um sistema de recirculação de água.

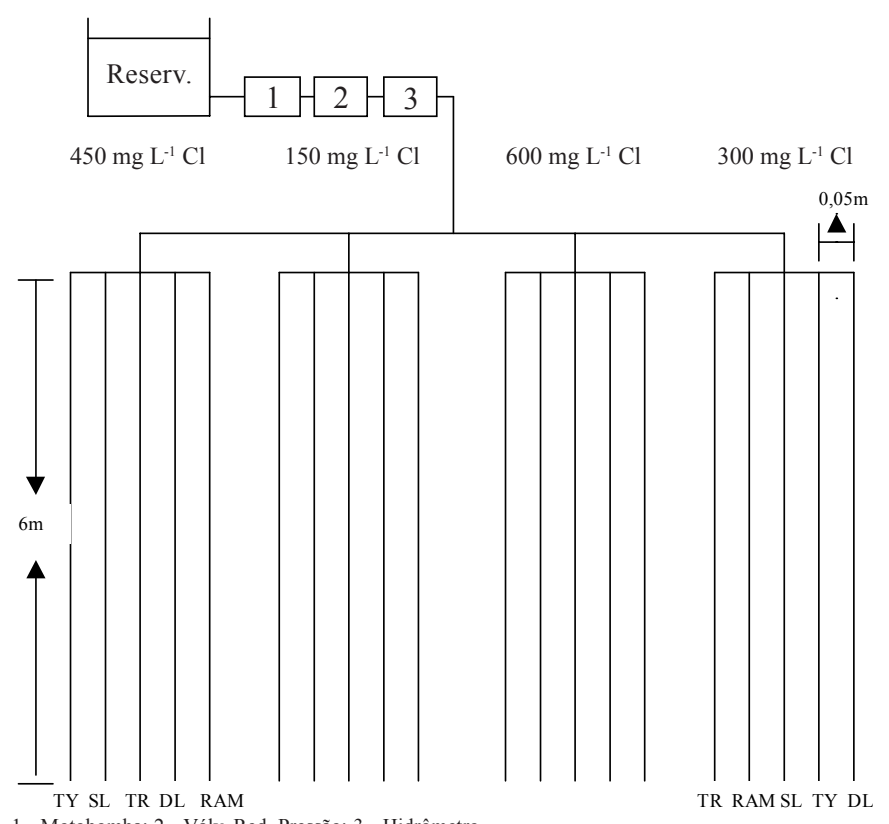

Figura 1. Esquema geral do ensaio

A determinação da vazão dos emissores após o tempo de funcionamento permitiu estabelecer-se o nível de entupimento, para cada modelo. Os gotejadores avaliados foram: Ram 17L (RAM), Streamline 100 (SL), Tiran 17 (TR), Typhoon 20 (TY) e Dripline 2000 (DL) todos da marca Netafim. Todos os emissores utilizados são do tipo câmara simples, percurso tortuoso, fluxo turbulento e apresentaram, em ensaios preliminares, coeficiente de uniformidade de fabricação - CV, inferior a $5 \%$ e os dados 
Tabela 1. Características técnicas* dos gotejadores estudados

\begin{tabular}{llccccc}
\hline Código & \multicolumn{1}{c}{ Modelo } & $\begin{array}{c}\text { Vazão } \\
\left(\mathrm{L} \mathrm{h}^{-1}\right)\end{array}$ & $\begin{array}{c}\text { Pressão } \\
(\mathrm{kPa})\end{array}$ & $\begin{array}{c}\text { Orifício } \\
(\mathrm{mm})\end{array}$ & $\begin{array}{c}\text { Espessura de } \\
\text { Parede }(\mathrm{mm})\end{array}$ & $\begin{array}{c}\text { Diâmetro } \\
\text { Interno }(\mathrm{mm})\end{array}$ \\
\hline SL & STREAMLINE 100 & 1,60 & 100 & 0,53 & 0,25 & 16,0 \\
RAM 17 & RAM 17 L & 2,30 & 100 & 1,04 & 0,62 & 14,6 \\
DL 2000 & DRIPLINE 2000 & 2,00 & 100 & - & 0,90 & 1,20 \\
TR & TIRAN 17 & 2,00 & 100 & 1,38 & 1,2 \\
TY & TYPHOON 20 & 1,75 & 100 & 0,71 & 0,50 \\
\hline
\end{tabular}

" Dados obtidos de catálogo do fabricante

técnicos relativos a cada modelo de emissor utilizado, encontram-se na Tabela 1.

Os tratamentos para recuperação dos emissores consistiram de aplicações de cloro à concentrações de 150, 300, $450 \mathrm{e}$ $600 \mathrm{mg} \mathrm{L}^{-1}$, na forma de hipoclorito de sódio $12 \%$, sendo que para cada dosagem avaliada foram realizadas duas aplicações, com intervalo, entre aplicações, de 1 dia. Os resultados foram comparados com aqueles obtidos ao final de $2160 \mathrm{~h}$ de operação do sistema.

O preparo da solução clorada foi efetuado em reservatório (Figura 1) sendo aplicada por $1 \mathrm{~h}$; o pH da solução foi monitorado e mantido entre 5,0 a 6,0, através da adição de ácido fosfórico $58 \%$, com o objetivo de se aumentar a proporção de ácido hipocloroso (maior poder germicida) na solução. A quantidade de ácido a ser adicionado foi obtida por titulometria da solução clorada, para cada concentração utilizada.

Ao término da aplicação, as linhas de emissores foram deixadas em repouso por $12 \mathrm{~h}$ e, logo após, efetuou-se a lavagem das redes, através da abertura de registros instalados nos finais de cada linha e, logo a seguir, procedeu-se à leitura das vazões individuais dos gotejadores.

As medições individuais da vazão dos gotejadores foram efetuadas com o uso de bateria de provetas montadas em uma base de madeira; antes da medição da vazão cada gotejador era cuidadosamente observado, no sentido de não permitir interferência de vazões provenientes de gotejadores adjacentes e/ou pontos de conexão. Barbantes foram utilizados para isolar a vazão de cada gotejador e, então, os volumes eram coletados por um período de $5 \mathrm{~min}$; uma calha retangular de PVC foi utilizada para cobrir, ao mesmo tempo, a bateria de provetas antes e no final do tempo de coleta.

Para efeito de avaliação da eficiência dos tratamentos foram analisados os seguintes parâmetros: a) vazão média dos emissores, expressa como percentual do valor nominal; b) percentual do número total de emissores, para cada modelo, por faixa de redução de vazão, sendo essas faixas estabelecidas como: $<5 \%$ (considerado sem entupimento), 5 - 15\%, $15-25 \%$, $25-35 \%, 35-45 \%, 45-55 \%, 55-65 \%, 65-75 \%, 75-85 \%, 85-95 \%$ e $>95 \%$ (considerado completamente entupido) da vazão nominal do gotejador e c) coeficiente de variação de vazão de emissores individuais $\left(\mathrm{CV}=100 \mathrm{sd} / \mathrm{q}_{\mathrm{m}}\right)$ onde sd é o desviopadrão das vazões medidas e $\mathrm{q}_{\mathrm{m}}$, a vazão média dos gotejadores.

A análise estatística foi efetuada fixando-se dosagem de cloro e modelo de gotejador, comparando-se apenas o efeito do número de aplicações do produto na recuperação da vazão dos gotejadores. O delineamento estatístico adotado foi o inteiramente casualizado, constando de três tratamentos (Sem Aplicação, S/APLIC, Aplicação 1, APLIC.1, e Aplicação 2, APLIC 2) e 50 repetições (gotejadores na linha), utilizando os testes F para análise de variância, e Tukey, para comparação de médias dos tratamentos.

\section{RESULTADOS E DISCUSSÃO}

\section{Vazão média de gotejadores}

Para melhor visualização do efeito dos tratamentos, os resultados de vazão média em termos de percentual da vazão nominal de cada modelo estão resumidos na Figura 2. O efeito do tratamento com cloro na vazão média dos emissores não foi uniforme para todos os modelos e dosagens estudadas. Os resultados de análise de variância e de comparação de médias entre número de aplicações, em função de dosagens de cloro, encontram-se na Tabela 2. Para o gotejador Streamline, a aplicação de cloro, contrariamente ao esperado, resultou em efeito depressivo da vazão, fato este observado para todas as dosagens avaliadas, sendo estatisticamente significativo somente para as dosagens de cloro de $150 \mathrm{e}$ $450 \mathrm{mg} \mathrm{L}^{-1}$, sem que houvesse diferença entre a primeira e a segunda aplicação.

Esse mesmo comportamento foi também observado para a dosagem de $150 \mathrm{mg} \mathrm{L}^{-1}$, no gotejador Ram, tanto na primeira como na segunda aplicação, e para o Dripline, na dosagem de $450 \mathrm{mg} \mathrm{L}^{-1}$, não sendo as diferenças de vazão; no entanto, são significativas pelo teste de Tuckey, no nível de 5\% de probabilidade. Para tal modelo, as dosagens de 300 e $600 \mathrm{mg} \mathrm{L}^{-1}$ redundaram em níveis de recuperação da vazão, semelhantes já na primeira aplicação, com diferença significativa em relação à situação sem aplicação; para a dosagem de $300 \mathrm{mg} \mathrm{L}^{-1}$, a variação de vazão foi de $91 \%$ para $97 \%$ da vazão nominal do modelo e a segunda aplicação, nesse modelo, mostrou ser detrimental, ou sem efeito significativo; a redução de vazão observada no gotejador Streamline, para todas as dosagens aplicadas, pode estar relacionada ao efeito da dissolução de material pela ação do cloro, anteriormente localizado nas paredes da mangueira. Este material, composto por mucilagem, decorrente do desenvolvimento bacteriano, ao ser dissolvido penetraria no gotejador, depositando-se ao longo do seu labirinto de percurso da água, o qual, dentre todos os modelos, apresenta as menores dimensões. Outra possibilidade, também observada por Ravina et al. (1992) seria a deposição, em um estágio inicial do entupimento, de mucilagem nos cantos do labirinto de passagem de água, alterando o regime de fluxo e resultando em vazão acima da nominal, como se observa para este modelo anteriormente à aplicação do cloro. Sendo assim, a redução de vazão observada poderia se relacionar com a remoção dessa mucilagem, pela ação do cloro, restabelecendo o regime de fluxo normal. 

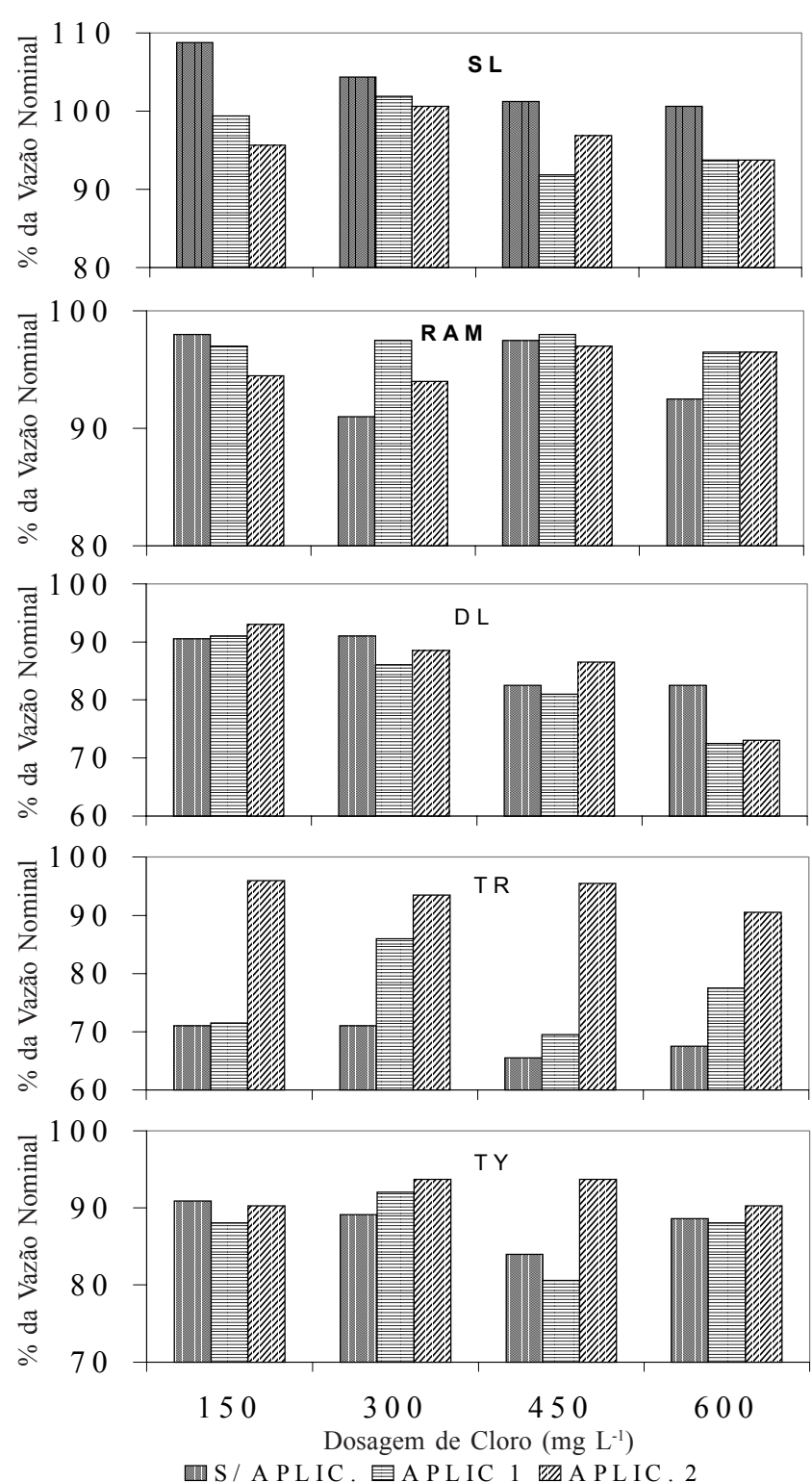

Figura 2. Vazão média expressa como percentual da vazão nominal (\%) de gotejadores, em função de dosagens e número de aplicações de cloro

Para o gotejador Dripline, a aplicação do cloro não resultou em efeito significativo de redução do entupimento, seja para as dosagens estudadas ou para o número de aplicações efetuadas; comportamento idêntico foi observado para o gotejador Typhoon, para o qual apenas a segunda aplicação da dosagem de $450 \mathrm{mg} \mathrm{L}^{-1}$ resultou em recuperação de vazão significativa, passando de 84 para $93 \%$ da vazão nominal do modelo. Não foi vislumbrada explicação para as diferenças de comportamento entre esses emissores, dada a semelhança na arquitetura dos mesmos.

Tendo-se destacado pela intensidade e pela uniformidade na ocorrência do entupimento, o gotejador Tiran apresentou comportamento diferenciado dos demais, com relação ao nível de recuperação da vazão. Para a primeira aplicação de cloro, apenas as dosagens de 300 e $600 \mathrm{mg} \mathrm{L}^{-1}$ aumentaram significativamente a vazão do emissor, em relação àquela antes da aplicação, enquanto a segunda aplicação resultou em uma vazão estatisticamente superior à primeira, para todas as
Tabela 2. Vazão média ${ }^{*}\left(\mathrm{~L} \mathrm{~h}^{-1}\right)$ de gotejadores obtidas sob diferentes dosagens e aplicações de cloro

\begin{tabular}{|c|c|c|c|c|}
\hline \multirow{2}{*}{ Aplicações } & \multicolumn{4}{|c|}{ Dosagens de Cloro, em $\mathrm{mg} \mathrm{L}^{-1}$} \\
\hline & 150 & 300 & 450 & 600 \\
\hline & \multicolumn{4}{|c|}{ SL } \\
\hline S/APLIC & $1,74 \mathrm{a}$ & $1,66 \mathrm{a}$ & $1,62 \mathrm{a}$ & $1,61 \mathrm{a}$ \\
\hline APLIC. 1 & $1,58 \mathrm{~b}$ & $1,63 \mathrm{a}$ & $1,46 \mathrm{~b}$ & $1,49 \mathrm{a}$ \\
\hline APLIC. 2 & $1,53 \mathrm{~b}$ & $1,61 \mathrm{a}$ & $1,55 \mathrm{ab}$ & $1,50 \mathrm{a}$ \\
\hline \multirow[t]{2}{*}{ CV (\%) } & 17,88 & 14,11 & 16,53 & 23,44 \\
\hline & \multicolumn{4}{|c|}{ RAM } \\
\hline S/APLIC & $1,95 \mathrm{a}$ & $1,82 \mathrm{~b}$ & $1,95 \mathrm{a}$ & $1,85 \mathrm{~b}$ \\
\hline APLIC. 1 & $1,94 \mathrm{a}$ & $1,95 \mathrm{a}$ & $1,95 \mathrm{a}$ & $1,93 \mathrm{a}$ \\
\hline APLIC. 2 & $1,88 \mathrm{a}$ & $1,88 \mathrm{ab}$ & $1,93 \mathrm{a}$ & $1,92 \mathrm{a}$ \\
\hline \multirow[t]{2}{*}{$\mathrm{CV}(\%)$} & 8,35 & 10,79 & 6,28 & 5,84 \\
\hline & \multicolumn{4}{|c|}{$\mathrm{DL}$} \\
\hline S/APLIC & $1,80 \mathrm{a}$ & $1,82 \mathrm{a}$ & $1,65 \mathrm{a}$ & $1,64 \mathrm{a}$ \\
\hline APLIC. 1 & $1,82 \mathrm{a}$ & $1,71 \mathrm{a}$ & $1,62 \mathrm{a}$ & $1,45 \mathrm{a}$ \\
\hline APLIC. 2 & $1,86 \mathrm{a}$ & $1,77 \mathrm{a}$ & $1,73 \mathrm{a}$ & $1,46 \mathrm{a}$ \\
\hline \multirow[t]{2}{*}{ CV (\%) } & 26,12 & 25,92 & 28,85 & 47,11 \\
\hline & \multicolumn{4}{|c|}{ TR } \\
\hline S/APLIC & $1,41 \mathrm{~b}$ & $1,41 \mathrm{c}$ & $1,31 \mathrm{~b}$ & $1,35 \mathrm{c}$ \\
\hline APLIC. 1 & $1,43 \mathrm{~b}$ & $1,71 \mathrm{~b}$ & $1,39 \mathrm{~b}$ & $1,54 \mathrm{~b}$ \\
\hline APLIC. 2 & $1,92 \mathrm{a}$ & $1,86 \mathrm{a}$ & $1,90 \mathrm{a}$ & $1,81 \mathrm{a}$ \\
\hline \multirow[t]{2}{*}{ CV (\%) } & 13,51 & 12,71 & 15,32 & 16,42 \\
\hline & \multicolumn{4}{|c|}{ TY } \\
\hline S/APLIC & $1,59 \mathrm{a}$ & $1,55 \mathrm{a}$ & $1,46 \mathrm{~b}$ & $1,55 \mathrm{a}$ \\
\hline APLIC. 1 & $1,54 \mathrm{a}$ & $1,60 \mathrm{a}$ & $1,41 \mathrm{~b}$ & $1,54 \mathrm{a}$ \\
\hline APLIC. 2 & $1,58 \mathrm{a}$ & $1,63 \mathrm{a}$ & $1,63 \mathrm{a}$ & $1,57 \mathrm{a}$ \\
\hline CV (\%) & 16,25 & 20,50 & 19,38 & 24,24 \\
\hline
\end{tabular}

"Médias seguidas pelas mesmas letras, dentro de uma mesma coluna, não diferem a nível de $5 \%$ de probabilidade

dosagens de cloro. O maior acréscimo de vazão, na primeira aplicação, ocorreu com a dosagem de $300 \mathrm{mg} \mathrm{L}^{-1}$, passando de $71 \%$, antes da aplicação, para $86 \%$ da vazão nominal, enquanto para a segunda aplicação a dosagem de $450 \mathrm{mg} \mathrm{L}^{-1}$ resultou em acréscimo de vazão de $30 \%$, com relação à situação sem aplicação, passando de $65 \%$ para $95 \%$ da vazão nominal. Os níveis de recuperação de vazão alcançados são similares àqueles obtidos por Nakayama (1977) tratando emissores com nível de redução de vazão de 25 a $50 \%$.

Um aspecto a se considerar na interpretação dos resultados de eficiência de recuperação de vazão entre as dosagens de cloro aplicadas, refere-se ao nível de redução de vazão encontrado anteriormente à aplicação. No caso do gotejador Ram, por exemplo, a primeira aplicação das dosagens, de 300 e $600 \mathrm{mg} \mathrm{L}^{-1}$, mostrou-se estatisticamente eficiente na recuperação da vazão, o que não ocorreu para a dosagem de 150 e $450 \mathrm{mg} \mathrm{L}^{-1}$, porém para esta última observa-se, através da Figura 2, que se partiu de um patamar de vazão bem mais elevado na situação sem aplicação, ou seja, as dosagens de 300 e $600 \mathrm{mg} \mathrm{L}^{-1}$ foram aplicadas quando o gotejador apresentava 91 e $92 \%$ de redução de vazão, respectivamente, enquanto na dosagem de $450 \mathrm{mg} \mathrm{L}^{-1}$, tal redução era de apenas $97 \%$; tal raciocínio pode também ser aplicado no caso da segunda aplicação, para o gotejador Typhoon, nas dosagens de 300 e $450 \mathrm{mg} \mathrm{L}^{-1}$.

Um vez que, ao final do processo de entupimento dos emissores cada modelo apresentava um nível de obstrução, o que constituiu uma situação inicial diferente para cada tratamento com dosagens de cloro, uma comparação estatística avaliando essas dosagens poderia apontar para a superioridade de determinada dosagem, 
apenas pelo fato dela estar vinculada a uma situação mais favorável (menor grau) de redução de vazão antes da aplicação do cloro, fato este que pode ser visualizado na Figura 2, onde se apresenta, para todos os gotejadores e dosagens de cloro, o percentual da vazão nominal na situação sem aplicação.

Apesar da ausência de uma análise, do ponto de vista estatístico, para o modelo Tiran, pode-se evidenciar, em função do maior nível de redução de vazão antes da aplicação, aliado a uma uniformidade maior dessa redução entre os diversos tratamentos, na situação sem aplicação, a superioridade do uso de duas aplicações de cloro; do mesmo modo, a similaridade de respostas na segunda aplicação sobre as demais, no nível de recuperação de vazão e sobre o coeficiente de variação de vazão (Figura 3) conduz à vantagem, do ponto de vista econômico, da dosagem de $150 \mathrm{mg} \mathrm{L}^{-1}$, enquanto a de $300 \mathrm{mg} \mathrm{L}^{-1}$ resultou nos maiores incrementos de vazão para os modelos Ram e Typhoon, bem como na menor redução, no caso do modelo Streamline.
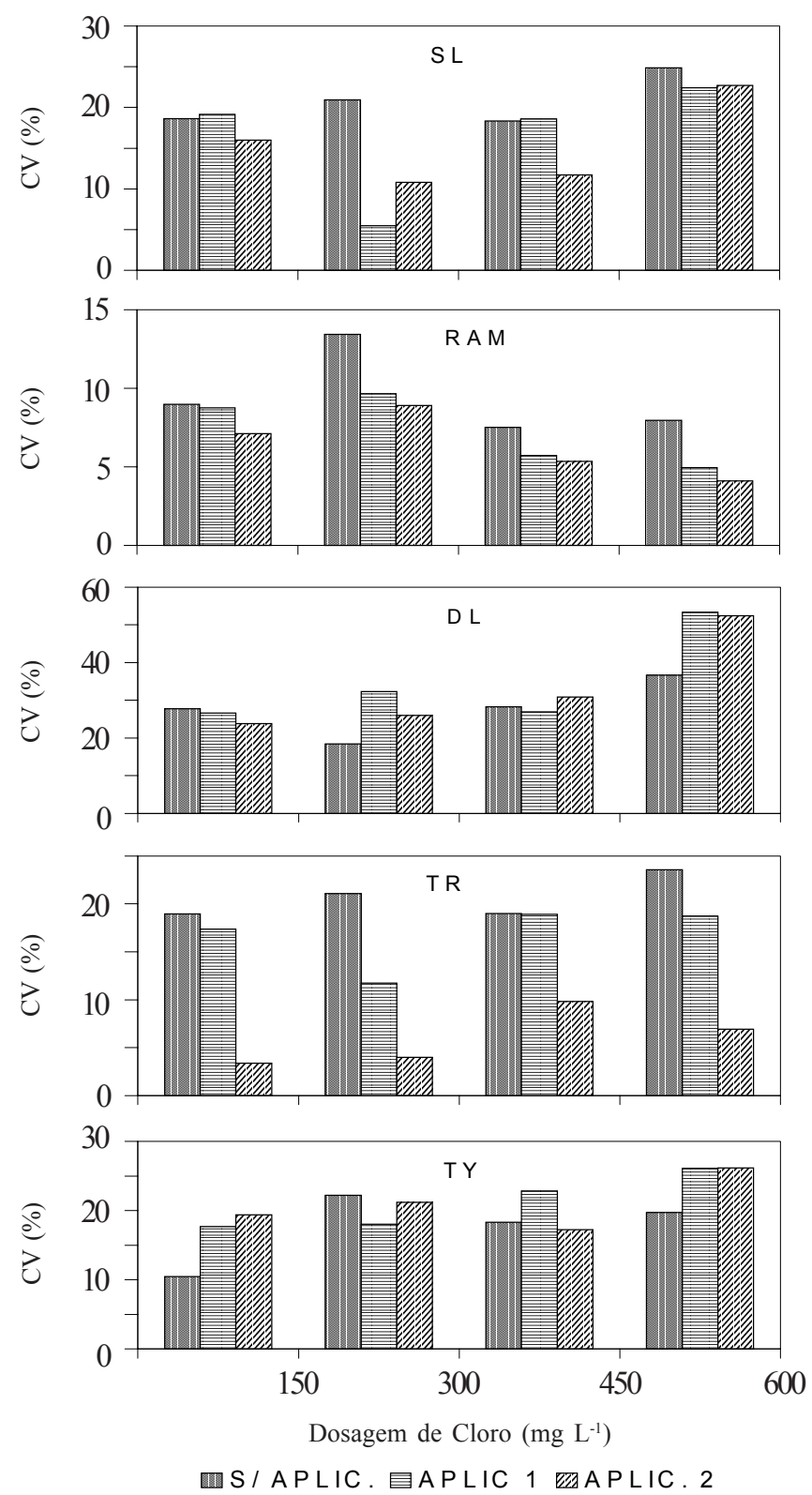

Figura 3. Coeficiente de variação $(\mathrm{CV})$ de gotejadores em função de dosagens e número de aplicações de cloro

\section{Uniformidade de emissão de água}

Da mesma forma que no parâmetro vazão média a aplicação de cloro mostrou comportamento diferenciado sobre o coeficiente de variação (CV) para os gotejadores avaliados, como se pode visualizar na Figura 3, o modelo Streamline, contrariamente ao que ocorrera com relação à vazão média, apresentou resposta favorável aos tratamentos, reduzindo o CV para todas as dosagens aplicadas. Tal redução mostrou-se mais pronunciada para a primeira aplicação da dosagem de $300 \mathrm{mg} \mathrm{L}^{-1}$, na qual o CV passou de 21 para $5 \%$; o mesmo efeito favorável das aplicações de cloro e o melhor desempenho da dosagem de $300 \mathrm{mg} \mathrm{L}^{-1}$ repetiram-se no modelo Ram, mesmo partindo-se de valores de CV, na situação sem aplicação, bem mais baixos.

Nos modelos Dripline e Typhoon, repetiu-se o efeito depressivo das dosagens nos valores de CV, como ocorrera com o modelo Streamline, com relação à vazão média. Este efeito mostrou-se mais pronunciado para as duas aplicações da dosagem de $600 \mathrm{mg} \mathrm{L}^{-1}$ em ambos os modelos e nas duas aplicações da dosagem de $150 \mathrm{mg} \mathrm{L}^{-1}$, para o gotejador Typhoon. O cálculo do CV apresenta elevada sensibilidade aos valores extremos na amostra, como no caso de emissores totalmente obstruídos. O modelo Dripline já apresentava, anteriormente ao tratamento com cloro, o maior percentual de gotejadores com entupimento total dentre todos os modelos, sendo que a aplicação de cloro resultou em aumento desse percentual, principalmente para as dosagens de 300 e $600 \mathrm{mg} \mathrm{L}^{-1}$, conforme visualizado na Figura 6. O melhor efeito do tratamento com cloro no aumento da uniformidade de emissão foi observado no modelo Tiran, no qual todas as dosagens estudadas apresentaram eficiência semelhante, tendo este efeito sido sentido mais marcadamente com a segunda aplicação de cloro.

\section{Distribuição do entupimento}

O percentual de emissores por faixa de redução de vazão refere-se a uma amostra de 50 gotejadores. Os valores apresentados nos eixos das abcissas nas Figuras 4 a 8, correspondem ao valor médio das faixas de redução de vazão estabelecidas. Para o modelo Streamline, as reduções observadas na vazão média, em função das dosagens de cloro (Figura 4) resultaram em pequeno reflexo na distribuição do entupimento; apenas a primeira aplicação da dosagem de $450 \mathrm{mg} \mathrm{L}^{-1}$ resultou em um aumento do percentual de emissores, com 10\% de redução de vazão.

Para o modelo Ram, o aumento da vazão média observado para as dosagens de 300 e $600 \mathrm{mg} \mathrm{L}^{-1}$ (Figura 5) refletiu-se principalmente na passagem de emissores da situação de $10 \%$ para zero por cento de redução de vazão, sendo o efeito contrário para a dosagem de $150 \mathrm{mg} \mathrm{L}^{-1}$.

No modelo Dripline, o efeito principal das dosagens também foi a passagem de emissores com $10 \%$ de redução de vazão para a faixa de redução zero (Figura 6) tendo este efeito sido mais efetivo para a segunda aplicação das dosagens de 450 e $150 \mathrm{mg} \mathrm{L}^{-1}$; tal tendência repetiu-se com bem mais evidência no gotejador Typhoon, em que a segunda aplicação, para todas as dosagens, resultou em aumento pronunciado do nível zero de entupimento e reflexo da diminuição do nível 

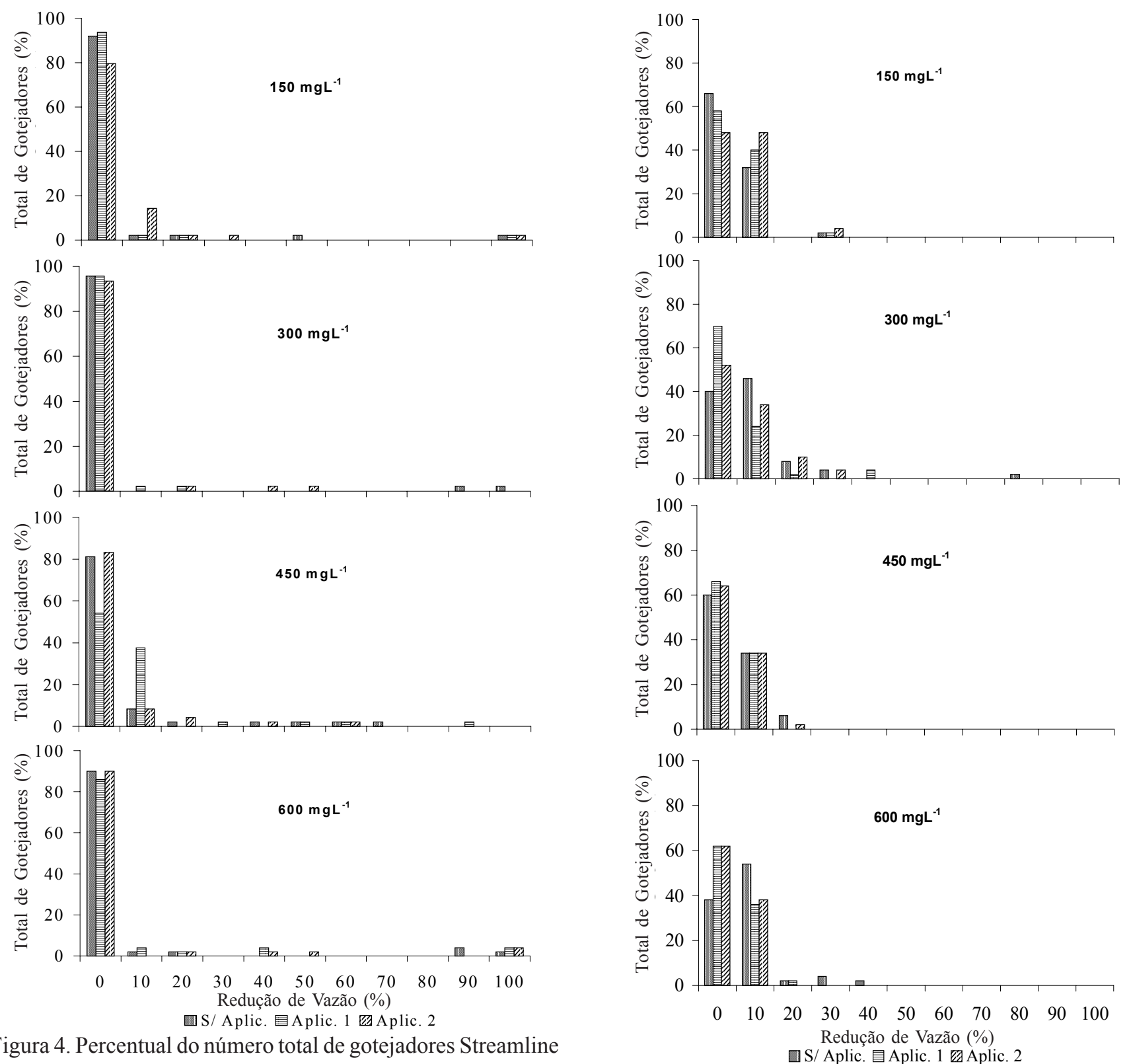

Figura 4. Percentual do número total de gotejadores Streamline $(n=50)$ por faixa de redução de vazão, em função de dosagens e número de aplicações de cloro

de $10 \%$ de redução de vazão (Figura 7). Nas aplicações de 300,450 e $600 \mathrm{mg} \mathrm{L}^{-1}$ este efeito foi mais evidente.

Para o gotejador Dripline, todas as dosagens, à exceção da menor, resultaram em aumento do percentual de emissores com entupimento total, tendo este efeito sido mais pronunciado para a dosagem de $600 \mathrm{mg} \mathrm{L}^{-1}$. Uma explicação provável para o aumento do entupimento total poderia ser a liberação de mucilagem, não totalmente dissolvida pela ação oxidante do cloro, das paredes dos tubos, mas esta hipótese não pôde ser comprovada experimentalmente e, como já observado, o fato foi de ocorrência restrita ao modelo Dripline. A aplicação de cloro não se mostrou eficiente na redução do entupimento total. Nakayama \& Bucks (1991) referem-se à baixa eficiência do tratamento de recuperação em gotejadores totalmente entupidos, pelo fato da água tratada com o químico não fluir através do emissor, onde a ação corretiva deve supostamente ocorrer.

Figura 5. Percentual do número total de gotejadores Ram ( $\mathrm{n}=$ 50) por faixa de redução de vazão, em função de dosagens e número de aplicações de cloro

O efeito do cloro no padrão de distribuição das vazões foi melhor observado no gotejador Tiran (Figura 8). Anteriormente ao tratamento com cloro, o modelo apresentava a quase totalidade dos gotejadores com reduções de vazão de $20 \%$ a $40 \%$. Após a primeira aplicação, apenas a dosagem de $300 \mathrm{mg} \mathrm{L}^{-1}$ resultou em aumentos expressivos de percentual de gotejadores na faixa de 0 a $10 \%$ de redução de vazão, enquanto para a segunda aplicação, no entanto, esta faixa de redução de vazão foi obtida para todas as dosagens avaliadas, tendo a dose de $450 \mathrm{mg} \mathrm{L}^{-1}$ resultando no aumento mais efetivo de emissores com nível zero de redução de vazão, alcançando $80 \%$ do total dos emissores. A semelhança na respostas ao tratamento com cloro para o modelo Tiran, resulta na vantagem econômica da dose de $150 \mathrm{mg} \mathrm{L}^{-1}$.

Um aspecto a se considerar quando da análise dos níveis de redução de vazão e de perda de uniformidade alcançados 

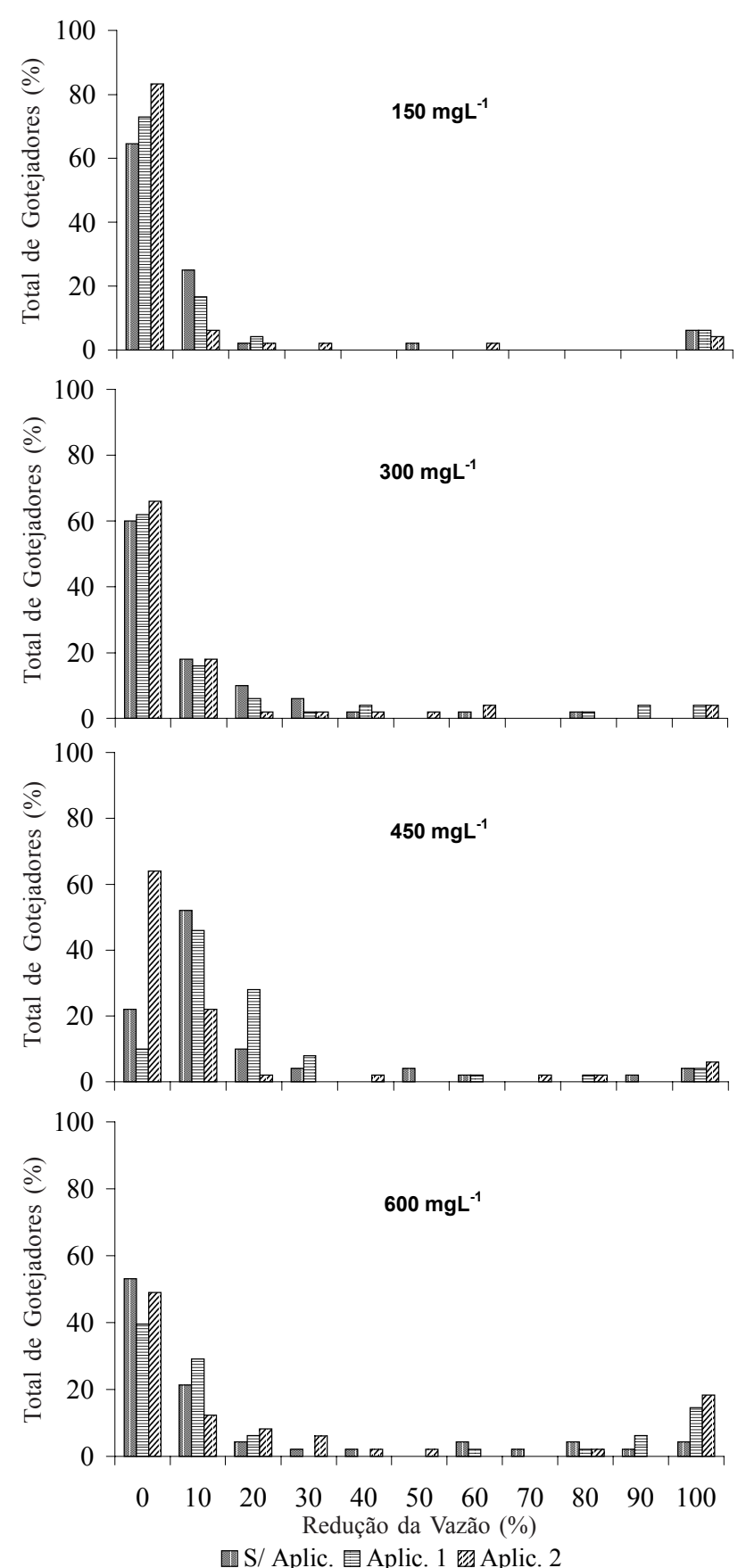

Figura 6. Percentual do número total de gotejadores Dripline $(\mathrm{n}=50)$ por faixa de redução de vazão, em função de dosagens e número de aplicações de cloro

por todos os emissores, foi a necessidade do uso de conectores de mangueira para permitir um espaçamento mínimo entre os gotejadores, possibilitando o aumento da população de emissores avaliados. Supõe-se que tal procedimento metodológico venha a influenciar na intensidade de formação de mucilagem e no conseqüente nível de agregação de material junto à reentrância formada entre o conector (união de mangueiras) e a parede da mangueira, através do aumento de pontos de adesão de biofilme.

Adicionalmente e além de características como diâmetro de orifício de passagem de água, turbulência do fluxo de água, vazão, mecanismos de auto-limpeza etc, outros fatores relacionados à arquitetura dos gotejadores, como comprimento
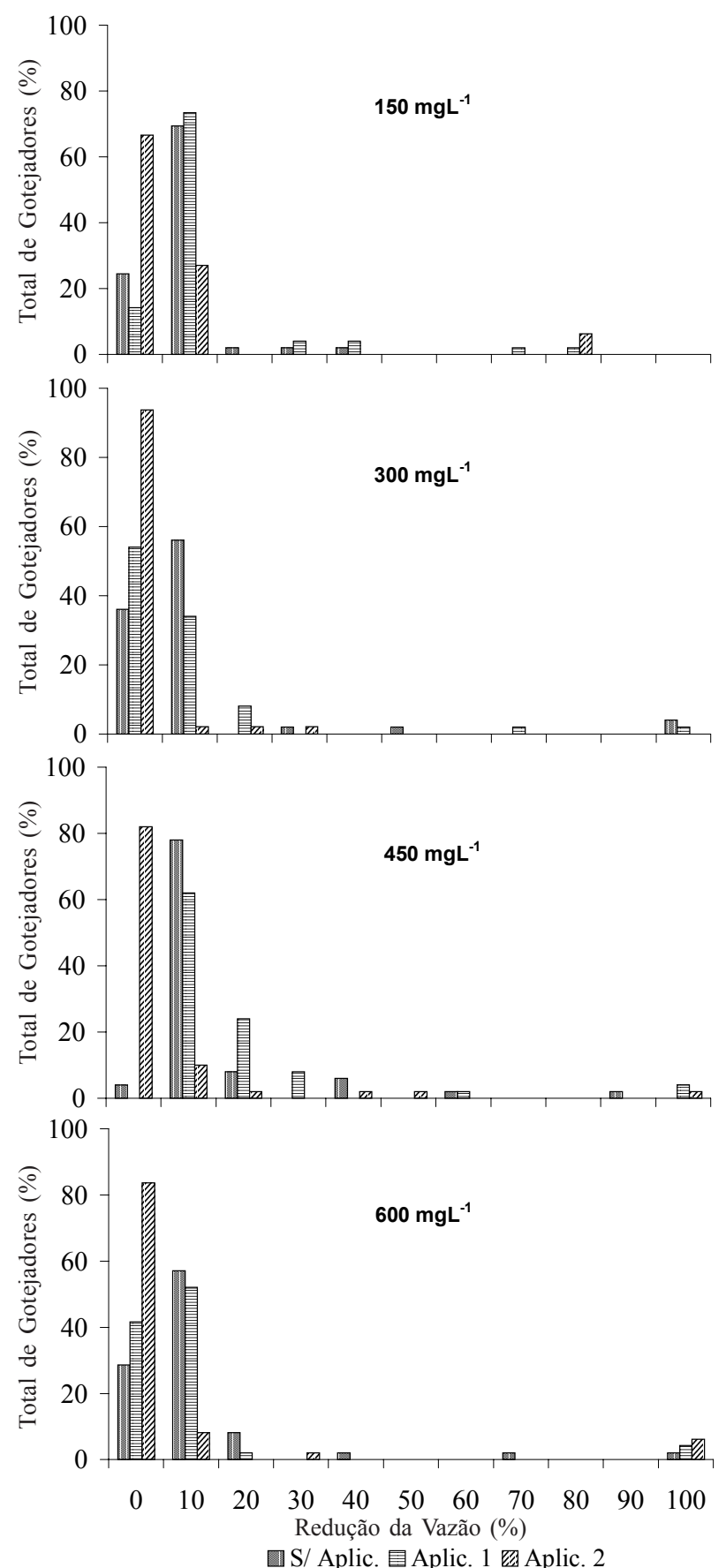

Figura 7. Percentual do número total de gotejadores Typhoon $(n=50)$ por faixa de redução de vazão, em função de dosagens e número de aplicações de cloro

do percurso da água na parte interna do emissor, área de filtragem, localização do orifício de entrada de água no emissor em relação à seção transversal e longitudinal da mangueira, além de posicionamento do emissor na mangueira (montagem na parte superior ou inferior do tubo) etc., podem ter determinado a diferença na suscetibilidade ao entupimento, observada para cada modelo avaliado.

\section{CONCLUSÕES}

1. Os resultados obtidos na condução do ensaio revelaram diferenças dos gotejadores avaliados, quanto à resposta tanto 


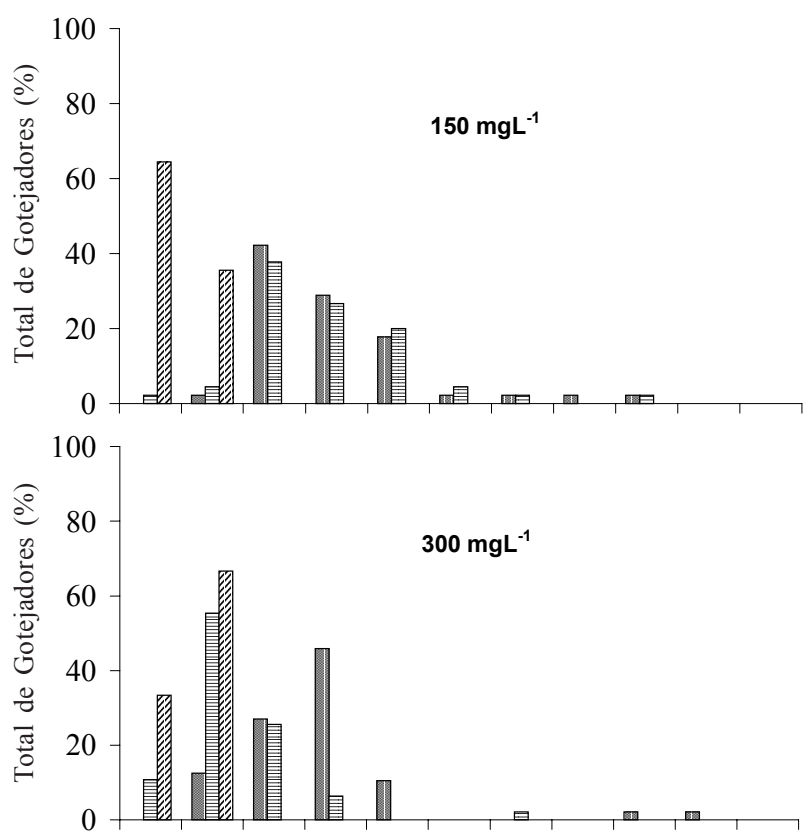

a dosagens como a número de aplicações, no tratamento de choque com cloro.

2. Para o gotejador Tiran, no qual se obteve a maior resposta aos tratamentos, a dosagem de $300 \mathrm{mg} \mathrm{L}^{-1}$ apresentou os resultados mais positivos.

3. A cloração da água foi efetiva para o entupimento parcial, não o sendo para emissores apresentando entupimento total.

\section{REFERÊNCIAS BIBLIOGRÁFICAS}

ENGLISH, S.D. Filtration and water treatment for micro-irrigation. In. INTERNATIONAL DRIP/TRICKLE IRRIGATION CONGRESS, 3, Fresno, 1985. Proceedings. St. Joseph: ASAE, 1985. p.50-57.

GILBERT, R.G.; FORD, H.W. Operational principles/emitter clogging. In: NAKAYAMA, F.S.; BULKS, D.A. Trickle irrigation for crop production . Amsterdam:Elsevier, 1986. cap.3.p.142-163.

GILBERT, R.G.; NAKAYAMA, F.S.; BUCKS, D.A. Trickle irrigation: prevention of clogging. Transactions of the ASAE, St. Joseph. v.22, p.514-519, 1979.
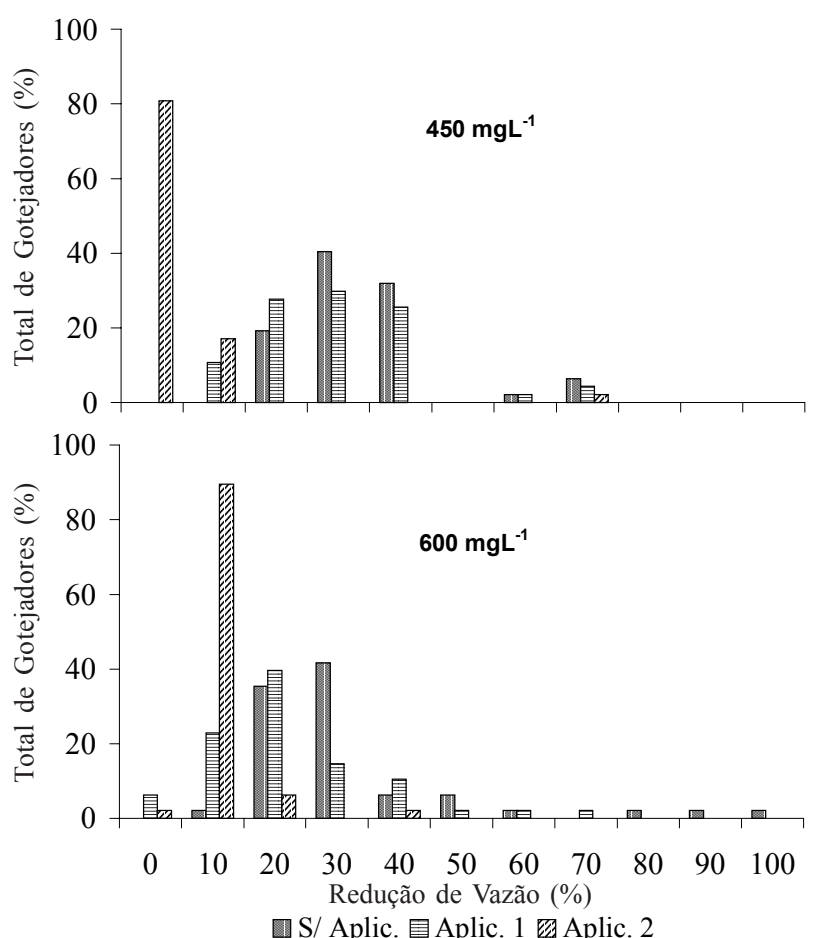

Figura 8. Percentual do número total de gotejadores Tiran $(\mathrm{n}=50)$ por faixa de redução de vazão, em função de dosagens e número de aplicações de cloro

GILBERT, R.G.; NAKAYAMA, F.S.; BUCKS, D.A.; FRENCH, O.F.; ADAMSON, K.C.; JOHNSON, R.M.. Trickle irrigation: predominant bacteria in treated Colorado river water and biologically clogged emitters. Irrigation Science, New York.v.3, p.123-132, 1982.

NAKAYAMA, F.S; BULKS, D.A. Emitter clogging effects on trickle irrigation uniformity. Transactions of the ASAE, St. Joseph. v.24. p.77-80, 1981.

NAKAYAMA, F.S.; BULKS, D.A. Water quality in drip/trickle irrigation: a review. Irrigation Science, New York v.12, p.187-192, 1991.

NAKAYAMA, F.S.; BUCKS, D.A.; FRENCH, O.F. Reclaiming partially clogged trickle emitters. Transactions of the ASAE. St. Joseph. v.20, p.278-280, 1977.

PADMAKUMARI, O.; SIVANAPPAN, R.K. Study on clogging in drip systems. In. INTERNATIONAL DRIP/TRICKLE IRRIGATION CONGRESS, 3., Fresno, 1985. Proceedings. St. Joseph: ASAE, 1985. p.80-83.

PIZARRO, F. Riegos localizados de alta frequencia. 3ed. Madrid: Ed. Mundi Prensa, 1996. 513p.

RAVINA, I.; PAZ, E.; SOFER, Z. MARCU, A.; SHISHA, A.; SAGI, G. Control of emitter clogging in drip irrigation with reclaimed wastewater. Irrigation Science, New York. v.13. p.129-139, 1992. 